\title{
The Influence of Flooding Phenomenon to Pressure Drop on Hotleg Simulator with $L / D=25$
}

\author{
Marcellinus Sindhu ${ }^{a}$, Apip Badarudin ${ }^{b}$, Indarto ${ }^{c}$, Deendarlianto ${ }^{d}$, Sinung Tirtha ${ }^{e}$, Venti Yoanita ${ }^{f}$ dan \\ Suprianta Setiawan Putra ${ }^{9}$ \\ ${ }^{c, d}$ Department of Mechanical Engineering and Industry, Gadjah Mada University \\ ${ }^{b}$ Doctoral Program of Mechanical Engineering, Gadjah Mada University \\ a,e,f Magister Program of Mechanical Engineering, Gadjah Mada University \\ ${ }_{9}$ Undergraduate Program of Mechanical Engineering, Gadjah Mada University \\ ${ }^{\mathrm{b}}$ Department of Refrigeration Engineering and Air Planning, State Polytechnic of Bandung \\ Jl. Grafika No. 2, Yogyakarta 55281, Indonesia \\ e-mail: marcellsh@gmail.com
}

\begin{abstract}
Cooling system in nuclear reactor is much influenced by counter-current flow. When a leakage is occurred, coolant in primary circuit of hotleg and hot steam from reactor will flows in counter-current condition. An experimental investigation has been performed to examine the effect of flooding phenomenon on the pressure drop. It was observed using acrylic complex pipe as hotleg simulator consisting of three parts: horizontal, bend and inclined pipe. Geometrical sizes of pipes was in scale of 1/30 of the actual hotleg geometrical size in the PWR with inner diameter=25.4 $\mathrm{mm}$, the horizontal pipe length $L=635 \mathrm{~mm}$, and inclined pipe length was $20 \mathrm{~mm}$ with an angle of $50^{\circ}$. Pressure drop was measured by using differential pressure sensor installed in the lower-tank (RPV simulator) and upper-tank (SG simulator). Pressure drop was observed before, during and after flooding. Based on the observation, it was found that the change of flow pattern is followed by the change of pressure drop. The results of this study were also compared with some correlations using the dimensionless superficial velocity parameter by Wallis correlation. Wallis correlation can be written as $J_{G}^{* \frac{1}{2}}+0,3974 J_{L}^{* \frac{1}{2}}=0,4832$.
\end{abstract}

Keywords: counter-current flow; pressurized water reactor; pressure drop

\section{INTRODUCTION}

Two phase flow (it may in form of gas-liquid, solid-liquid, and solid-gas phase) was categorized as multiphase flow. In many industrial applications such as oil and gas, refrigeration equipment, condenser, production of chemical and food processing, nuclear and geothermal power plant, and others, the phenomenon of multiphase flow can be found. In nuclear power plant, two phases flow also occurred in Pressurized Water Reactor (PWR) as shown in Figure 1.1. When loss-of-coolant-accident (LOCA) which caused by depressurization was occurred because of leakage on primary piping, steam will be generated in PWR. The steam will flow into SG by hot-leg pipe. When arrives at SG (inside primary pipe), steam will be condensed. The condensate then flows into hotleg pipe into RPV. As result, in hot-leg pipe, counter current of steam and water was generated.

The success of cooling of nuclear reactor in primary piping is depending on behavior of two phase counter current. Counter current of gas and liquid only stable for certain value limit of mass flow rate. When mass flow rate of steam increase to much, a portion of cooling fluid experience flow back to steam generator. The phenomenon is known as Counter Current Flow Limitation (CCFL) or start of the occurrence of flooding. When flooding phenomenon is not adequately managed then cooling of reactor will fail. 


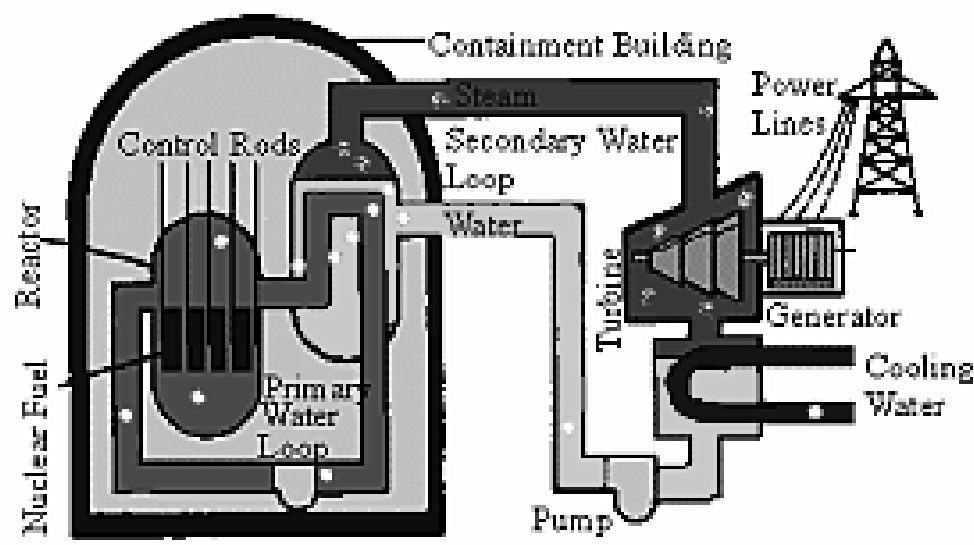

Figure 1.1 Scheme of Pressurized Water Reactor

Hewitt et.al. [3] measured gradient of pressure for two phase counter current in vertical pipe. From the research, it can be concluded that measuring of pressure gradient was a good indicator in accurate detection of the occurrence of onset of flooding. Flooding can be characterized by visual observation and pressure drop [9]. Wongwise [9] defined the onset of flooding is a point when mass flow of gas and liquid phase can not be increased anymore in steady state counter-current flow. Flooding phenomenon in two phase counter-current of water-air, according to Deendarlianto, et.al. (2008), was indicated as maximum rate of air mass flow which flow into inlet. Another definition of flooding was stated by Issa [5] as a condition when increase in air mass flow followed by stop of water flow carried by air flow partially or wholly. Flooding phenomenon may occurred in geometry of vertical pipe or horizontal one. The phenomenon can be observed by visual observation, liquid flow rate and pressure gradient.

Research on phenomenon of flooding in counter-current flow of water-air has been conducted by researchers. Many researchers did the research by modelling of hot-legpipe with various geometry and size to observe occurrence of flooding phenomenon. There were correlations in research report literatures on flooding. But uncertainty in mechanism of flooding makes the phenomenon still need to be investigated. This research was focused on characterization of two phase counter-current flow which flow in complex pipe based on measurement of pressure drop.

Wallis [8] proposed dimensionless parameter $\mathrm{JK}^{*}$ which define superficial velocity of gas and liquid which related to velocity of gas when flooding was generated. This parameter was a comparison between inertial force and hydrostatic force and defined as:

$$
I_{K}^{*}=J_{K} \sqrt{\frac{\rho_{K}}{g D\left(\rho_{L}-\rho_{L}\right)}}
$$

To show the velocity of each phase then flux volumetric or superficial velocity was used as comparison of volumetric mass flow to total area of flow:

$$
l_{K}=\frac{Q_{K}}{A}
$$

With $\rho$ indicate density, $\mathrm{g}$ gravitational speed and $\mathrm{D}$ diameter of pipe. By indicating those parameters, Wallis proposed equation related to CCFL as:

$$
l_{G}^{* 1 / 2}+m J_{L}^{* 1 / 2}=C
$$

Value of $\mathrm{m}$ is depending on physical properties of liquid and gas, while $\mathrm{C}$ is depending on experimental conditions especially inlet and outlet condition of working fluids. When inlet and outlet condition of fluids is smooth enough the $C$ is equal to 1 . 


\section{Methodology}

Observation of flooding phenomenon in complexes pipe as hot-leg simulator was conducted by controlling volumetric flow rate of water to be constant at first. Air volumetric mass flow then increased gradually and periodically (every 15 seconds) until condition of onset of flooding to zero-liquid penetration was occurred, as shown in Figure 2.1 for Region I and Region II.

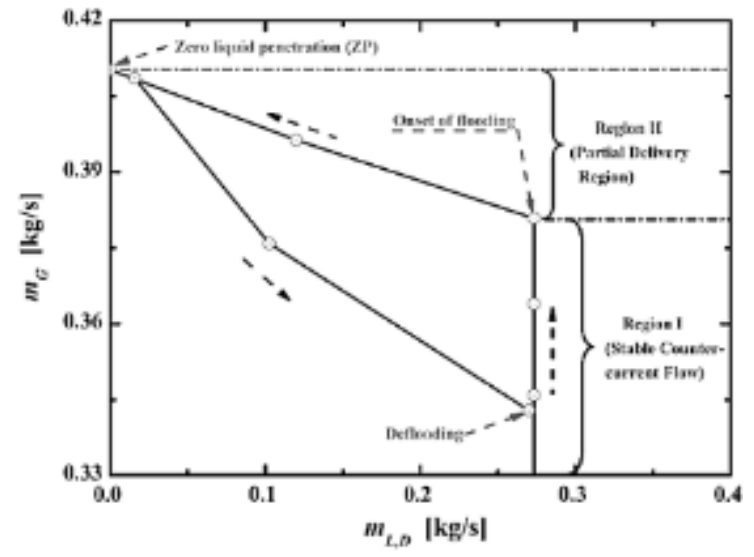

Figure 2.1 Terminology of two phase counter-current flow of gas-liquid (Deendarlianto et.al. [2])

Installation of experiment was consisted of equipment to control water flow, equipment to control air, and equipment of testing section. Scheme of experimental design was depicted in Figure 2.2.

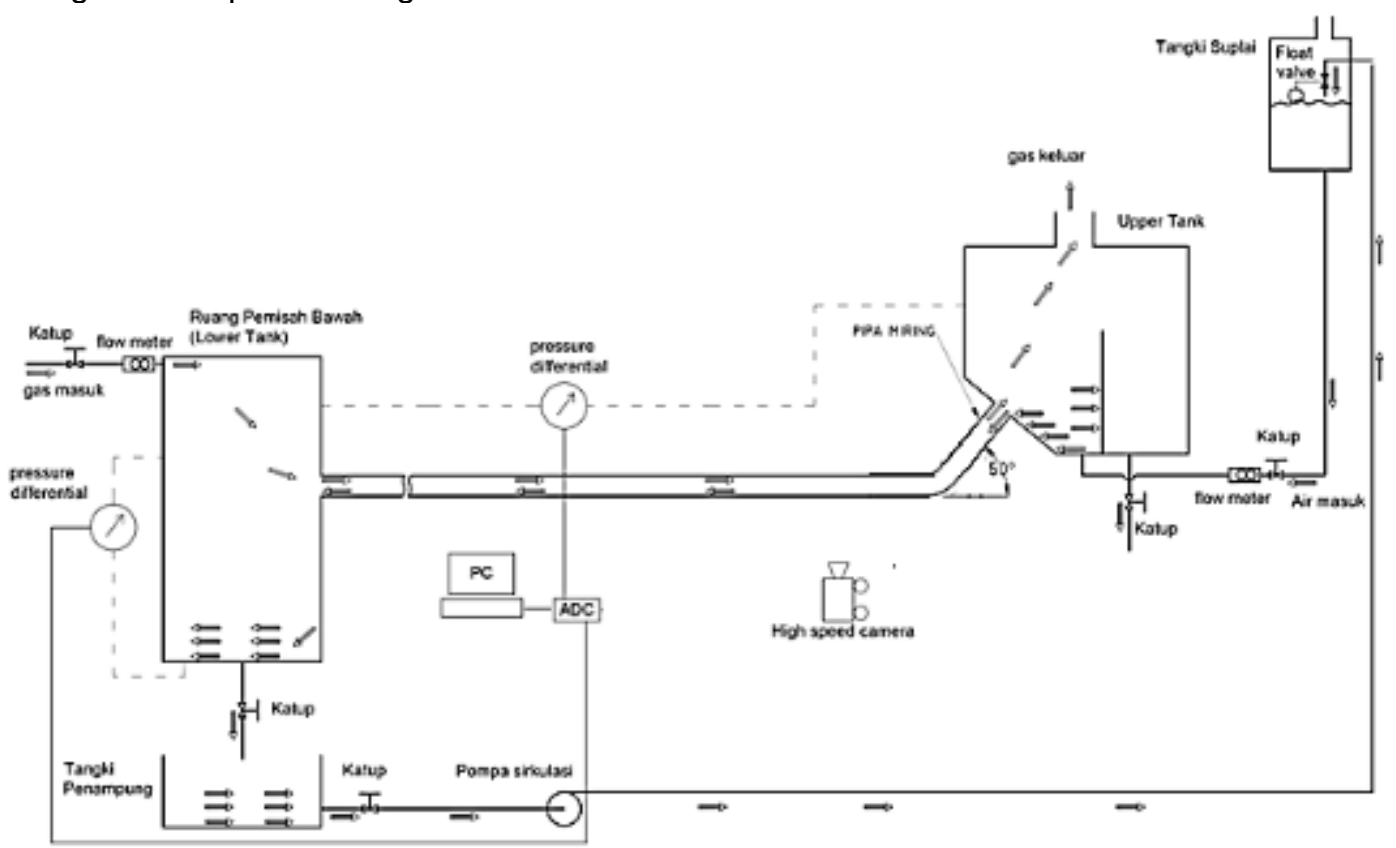

Figure 2.2 Scheme of experimental installation

Liquid in form of water was pumped from reservoir tank to supply tank. After water was collected in sufficient amount in supply tank, the pump was turned off. Water then flow into upper tank (as simulator of steam generator) by controlling of water flowmeter opening. From upper tank, water was flow into complex pipe and ended in lower tank (as simulator of reactor pressure vessel). Complex pipe was replica of hotleg in form of 
horizontal pipe with $L / D=25\left(\frac{635 \mathrm{~mm}}{25.4 \mathrm{~mm}}\right)$, elbow/bend and inclined pipe (50 to horizontal line). Meanwhile air from compressor was flown into regulator to be controlled for contact air pressure. After passing regulator, air then flows into air flowmeter to lower tank and flow in counter current with the direction of water flow in complex pipe and ended in upper tank.

Pressure drop of two phases between lower-tank and upper-tank was measured in differential pressure transmitter made by The Validyne Model P55. Current output signal from the transmitter then transformed by Analog to Digital Converter (ADC) in Data Acquisition System from National Instrument to pressure signal as function of time. Data acquired from DAQ then presented, stored, and processed by using Personal Computer (PC).

\section{Results and Discussion}

\subsection{Basic Characteristic of Counter-current Flow in Hotleg}

From visual data taken by high speed camera, basic characteristic of counter current flows in complex pipe can be observed. High and low of air and water flow rate will form different flow pattern, such as stratified flow, stratified-wavy flow, slug flow, and churn flow.

When gas mass flow was low, it means that flow rate of air was relatively low for certain water flow rate as observed in divided interface of water and air with air in upper part and water in lower part. In this condition, flow pattern was stratified flows and have relationship with gravity. A stratified flow was depicted in Figure 3.1 (a). In inclined section and elbow of hotleg, the water layer was thin. Flowing water from upper tank was accelerated in inclined section because of gravity influence.

When air flow rate was increased further, interface border became unstable. The size of generated wave has direct relation with magnitude of air mass flow rate. The generated flow pattern was stratified-wavy, as shown in Figure 3.1. (b).

With the increased of air mass flow rate, the onset of flooding will occur and marked by onset of slugging. Slug flows will occurred when wave touch upper limit of pipe and then pushed back by air. Flow pattern of slugn was depicted in Figure 3.1 (c). In inclined section, the churn flow was occurred and marked by small bubbles which followed by droplet flow into upper tank as depicted in Figure 3.1 (d).
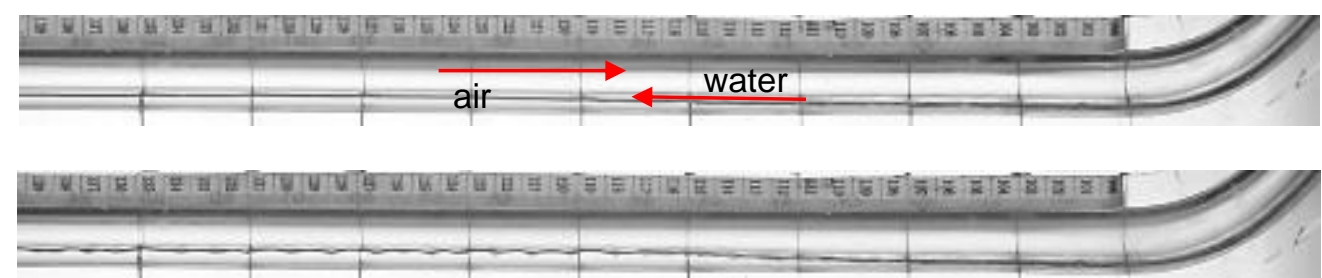

(a) Stratified flow pattern for $\mathrm{JG}=0 \mathrm{~m} / \mathrm{s}$ and $\mathrm{JL}=0.020 \mathrm{~m} / \mathrm{s}$
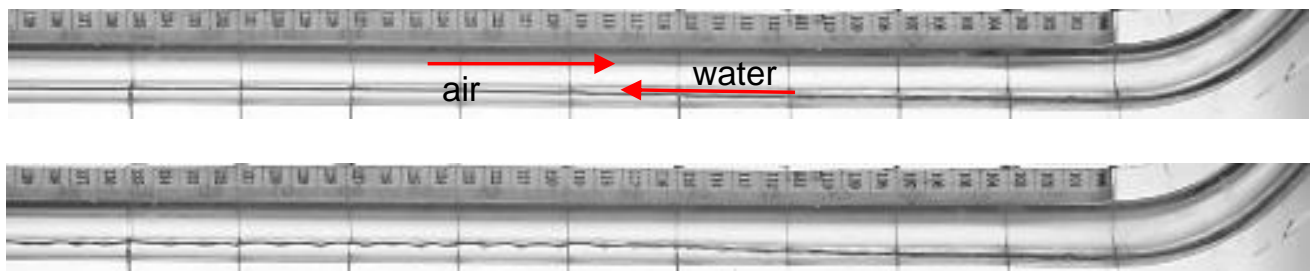

(b) Stratified-wavy flow pattern for $\mathrm{JG}=1.97 \mathrm{~m} / \mathrm{s}$ and $\mathrm{JL}=0.020 \mathrm{~m} / \mathrm{s}$

Figure 3.1 (a)-(c) Changes of flow pattern of counter current flow for $J_{L}=0.02 \mathrm{~m} / \mathrm{s}$ 


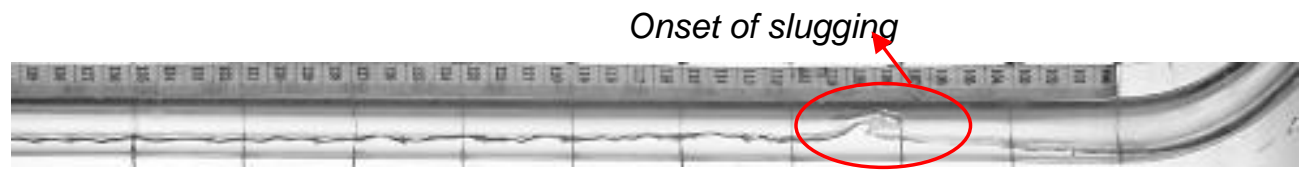

(c) Slug flow pattern for $\mathrm{JG}=2.47 \mathrm{~m} / \mathrm{s}$ and $\mathrm{JL}=0.020 \mathrm{~m} / \mathrm{s}$

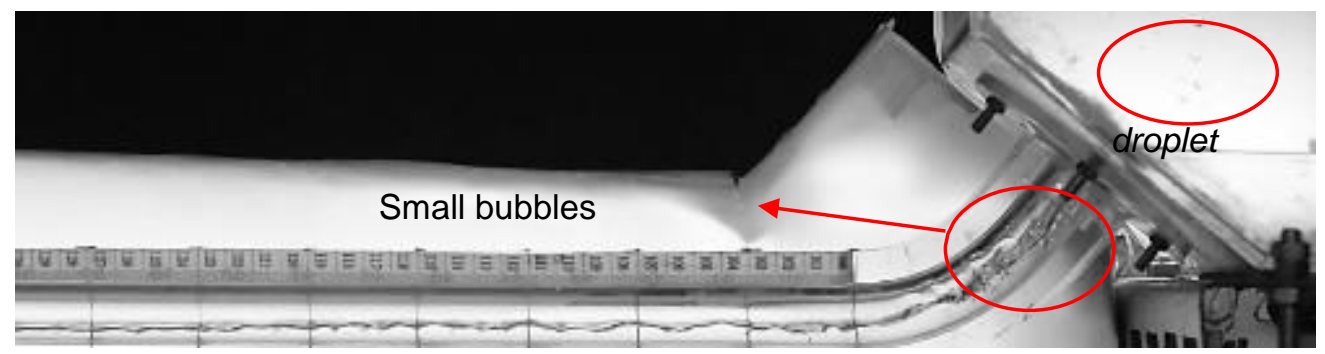

(d) Churn flow pattern and droplet generation for $\mathrm{JG}=2.47 \mathrm{~m} / \mathrm{s}$ dan $\mathrm{JL}=0.020 \mathrm{~m} / \mathrm{s}$

Figure 3.1 (a)-(c) Changes of flow pattern of counter current flow for $J_{L}=0.02 \mathrm{~m} / \mathrm{s}$ (continued)

When change of flow pattern was occurred, pressure drop between upper tank and lower tank also changed. When in stratified pattern, pressure drop will increase slowly as superficial velocity increase every 15 second. The increase has tendency to follow linear one. Pressure drop when in stratified pattern increased slowly because film thickness also increased so that area of air flow was decreased. When in wavy pattern, gradient of pressure drop became higher than in stratified pattern. Increase of pressure drop has positive correlation with increasing of size and amount of bubbles. When slug was generated as start of flooding, pressure drop will suddenly increase. Figure 3.2 depicted correlation between time $(\mathrm{s})$ with pressure drop $(\mathrm{kPa})$ with superficial velocity of water was constant $(\mathrm{J} L=0,020 \mathrm{~m} / \mathrm{s})$.

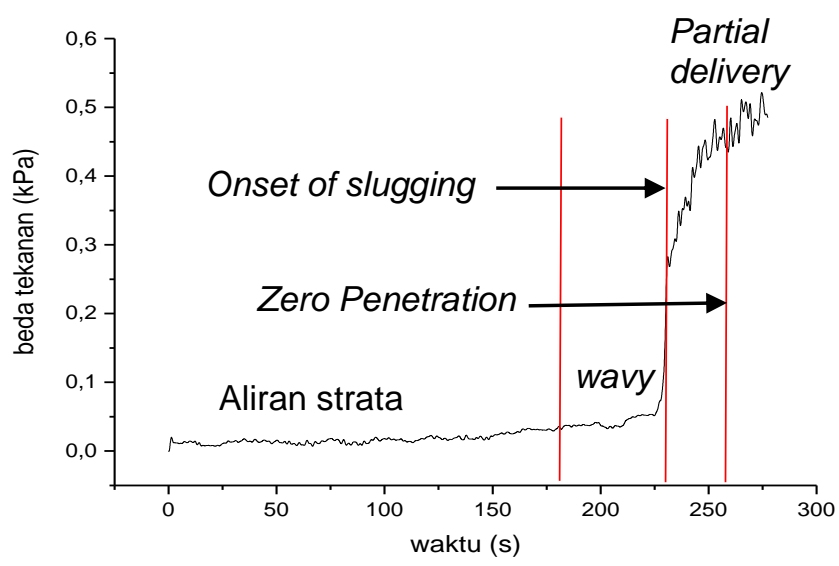

Figure 3.2 Relationship between pressure drop and time for $J_{L}=0.02 \mathrm{~m} / \mathrm{s}$

In Figure 3.3, it can be shown that relationship between average of pressure drop $(\triangle P)$ with superficial velocity of air $\left(J_{G}\right)$ in superficial velocity of water $J_{L}=0.02 \mathrm{~m} / \mathrm{s}$; $\mathrm{J} L=0.053 \mathrm{~m} / \mathrm{s}$; and $\mathrm{J}=0.092 \mathrm{~m} / \mathrm{s}$. In the Figure 3.3 also was shown point of onset of flooding. The point was refers to definition of Wongwises (1996), in which onset of 
flooding was marked by onset of flooding. It was shown that before flooding, the changes of average of pressure drop of flow pattern for each increase of $J_{G}$ was linier in trending with small gradient. After superficial velocity of air was increased further, flooding was occurred and slope changes increase drastically. In average, the pressure drop at the moment before flooding (when in stratified pattern or wavy, when flooding, and after flooding) has tendency to be higher than value of higher $\mathrm{J}$.

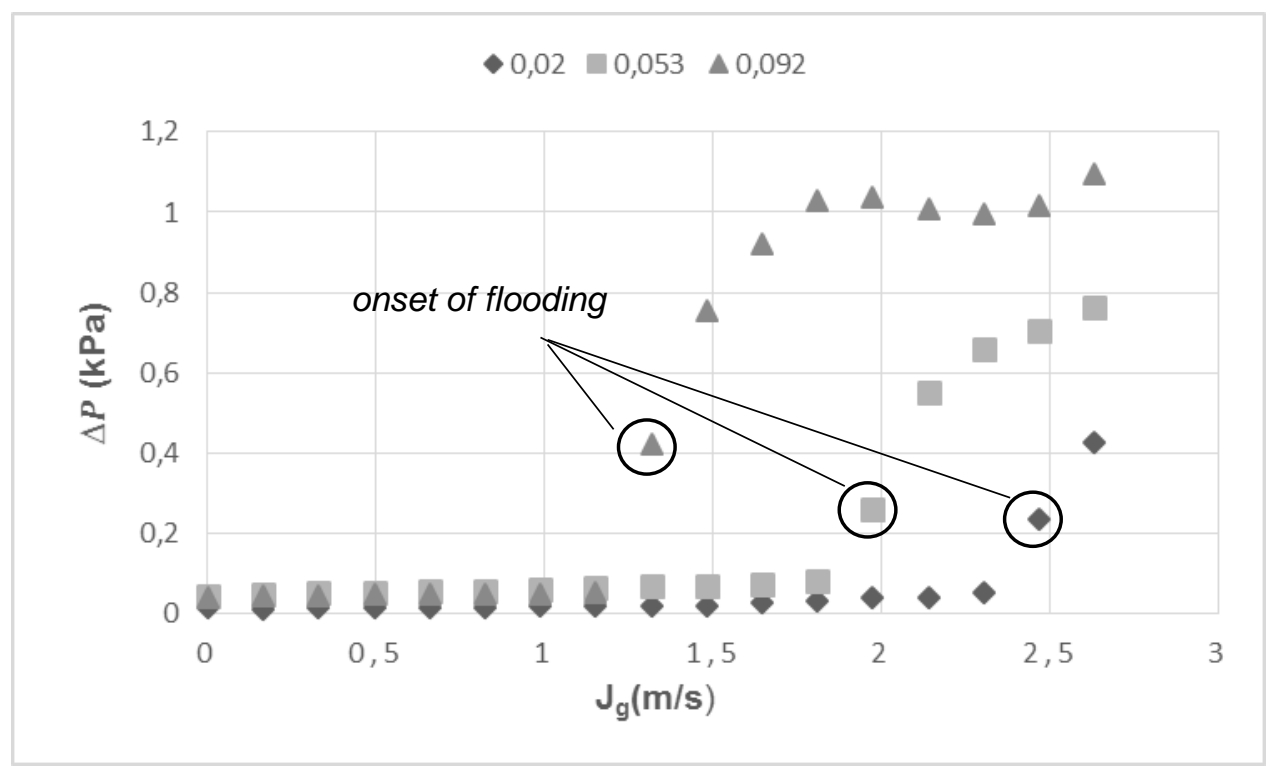

Figure 3.3 Relationship between averages of pressure drop $(\Delta P)$ with air superfisial velocity $\left.V_{G}\right)$

\subsection{Correlation of Superficial Velocity to Onset of Flooding}

Mechanism of flooding is a function of superficial velocity of water [10]. Wongwises [10] divide 3 (three) region with relation of $l_{i}^{* 0.5}$ and $l_{G}^{* 0.5}$ for flooding point based on differential mechanism. In this research, occurrence of onset of flooding has tendency as shown in Figure 7. In this research, the comparison between length of horizontal pipe and diameter of pipe (L/D) was 25. Air flow rate for occurrence of onset of flooding was decrease following increase of water flow rate. Graph of onset of flooding when compared with previous research has similar tendency with graph from Apip and Hadipranoto's research, the difference was in inclination of line in this research was smaller and curve position above the previous graph. When written in Wallis correlation, the equation become $l_{G}^{* 1 / 2}+m J_{L}^{* 1 / 2}=C$, with $\mathrm{m}=0.3974 \mathrm{~d}$ and $\mathrm{C}=0.4832$. It can be said that flooding was easier for higher water flow rate. In line with increase of water superficial velocity, the thickness of film thickness was increased. Area of air flow in pipe became smaller so that air flow became faster in hitting the peak of higher hydraulic jump. The effect was occurrence of bubble in the peak of hydraulic jump which will grow into slug.

There was different realization for different L/D. This was show that the geometrical comparison between length of horizontal pipe to diameter of pipe influence initiation of flooding, i.e. occurrence of slug. When comparing in whole, on set flooding was occurred faster for bigger L/D. According to Al Issa and Macian [4], this was caused by friction of water flow was higher than pipe was longer and makes thickness of film fluid near elbow become higher. This condition made flooding which initiated by slug generation on peak of hydraulic jump become occurred faster. 


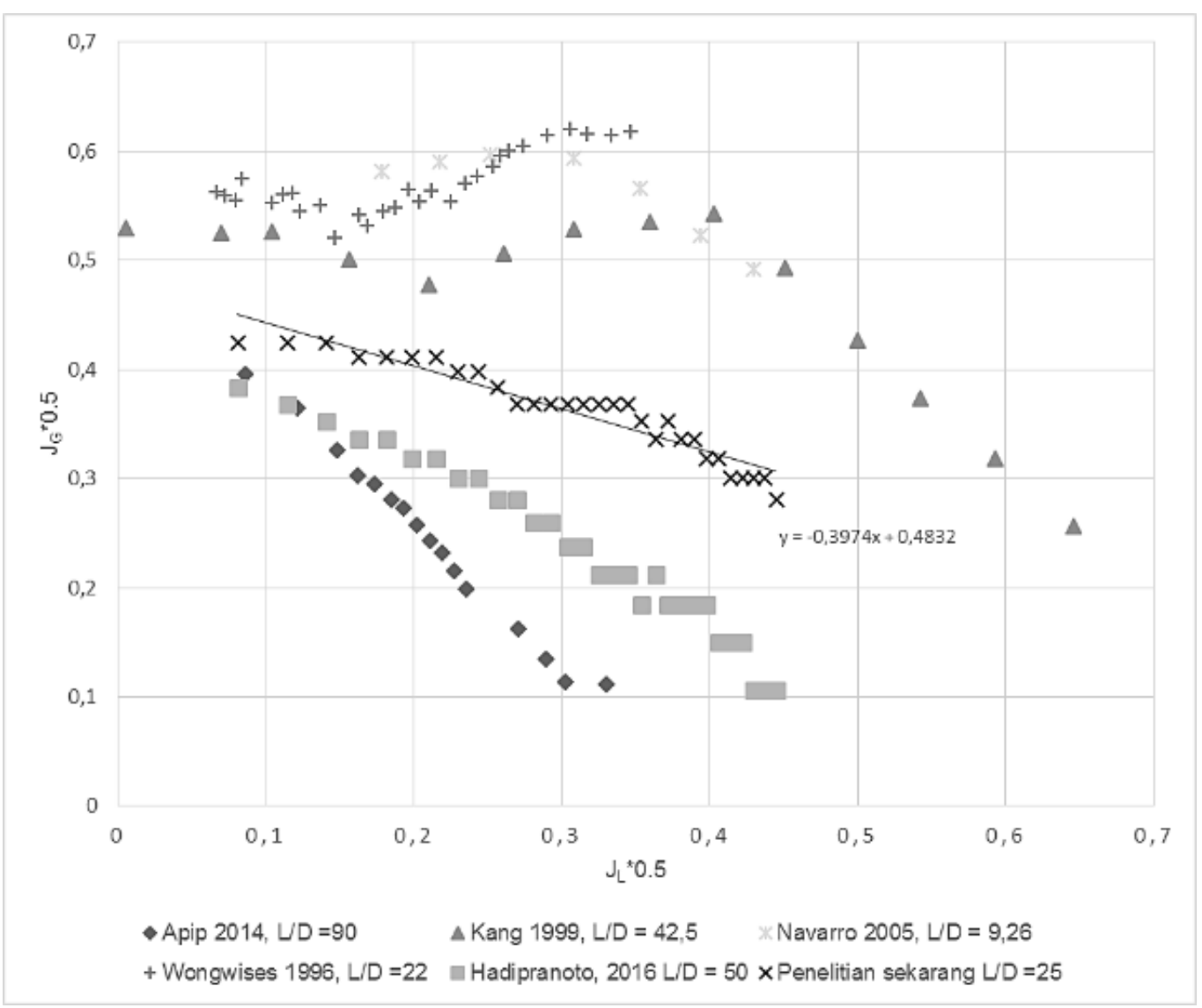

Figure 7 Comparison of onset of flooding curve

\section{CONCLUSION}

Based on the research in investigating counter current flow of water-air in complex pipe, it can be conclude that:

a. When in stratified pattern, the pressure drop increased slowly following the increase of superficial increase of air. When in wavy pattern, the increase of pressure becomes higher. When slug was occured as initiation of flooding, the preesure drop between upper and lower tank was increased drastically. With higher superficial velocity of water $(\mathrm{J} L)$, slope changes of presure drop increased drastically and faster, showing faster occurence of flooding. Average of pressure drop has tendency to be higher for highe value of $\mathrm{J}$.

b. Air flow rate for the occurence of onset of flooding was decreasing in line with increasing of water flow rate. When expressed in Wallis correlation, it can written as $J_{G}^{* \frac{1}{2}}+0,3974 J_{L}^{\frac{1}{2}}=0,4832$.

\section{REFERENCES}

[1] Apip, Indarto, Deendarlianto, "Observasi karakteristik CCFL pada pipa kompleks", ReTII IX, 2014, hal 371-375.

[2] Deendarlianto, Vallée, C., Lucas, D., Beyer, M., Pietruske, H., Carl, H., "Experimental Study on the Air/water Counter-current Flow Limitation in a Model of the Hot Leg of a Pressurized Water Reactor", Nuclear Engineering and Design, Vol. 238 (12), 3 hal 389-3402, 2008. 
[3] Hewitt, G.F., Lacey, P.M.C, Nicholls,B., "Transition in Film Flow in a vertical pipe", UKAEA Report AERE-R4022, Harwell, England, 1965.

[4] Issa, S., Macian, R., "A review of CCFL phenomenon, Annals of Nuclear Energy", Elsevier, Vol. 38, pp. 1795-1819, 2011.

[5] Issa, S., Macian, R., "Experimental investigation of countercurrent flow limitation (CCFL) in large-diameter hot-leg geometry : A detailed description of CCFL mechanism, flow pattern and high quality HSC imaging of the interfacial structure in a 1/3.9 scale of PWR geometry", Nuclear Engineering and Design, Elsevier, Vol. 280, pp. 550-563, 2014.

[6] Kang, S.K., Chu, I.C., No, H.C., Chun, M.H., "Air-water countercurrent flow limitation in a horizontal pipe connected to an inclined riser", Journal of the Korean Nuclear Society, Vol. 31 (6), 548-560, 1999.

[7] Navarro, M., "Study of countercurrent flow limitation in a horizontal pipe connected to an inclined one", Nuclear Engineering and Design Vol. 235, no. 10-12, pp. 1139-1148, 2005.

[8] Wallis, G.B., "One-dimensional Two-phase Flow", Mc Graw Hill, New York, pp. 336-345, 1969.

[9] Wongwises, S., "Experimental Investigation of Two-Phase Countercurrent Flow Limitation in a Bend between Horizontal and Inclined Pipes", Experimental Thermal and Fluid Science, Volume 8, pp. 245-259, 1994.

[10] Wongwises, S., "Flooding in a horizontal pipe with bend", Int.J.Multiphase Flow Vol 22, pp. 195-201, 1996. 